\title{
The Association Between Fall History and Physical Performance Tests in the Community- Dwelling Elderly: A Cross-Sectional Analysis
}

Jin Chul Kim, $\mathrm{MD}^{1}$, Jinmann Chon, $\mathrm{MD}, \mathrm{PhD}^{1}$, Hee Sang Kim, MD, PhD ${ }^{1}$, Jong Ha Lee, MD, PhD ${ }^{1}$, Seung Don Yoo, MD, $\mathrm{PhD}^{1}$, Dong Hwan Kim, MD, $\mathrm{PhD}^{1}$, Seung Ah Lee, MD, $\mathrm{PhD}^{1}$, Yoo Jin Han, $\mathrm{MD}, \mathrm{PhD}^{1}$, Hyun Seok Lee, $\mathrm{MD}^{1}$, Bae Youl Lee, $\mathrm{MD}^{1}$, Yun Soo Soh, $\mathrm{MD}^{1}$, Chang Won Won, MD, PhD ${ }^{2}$

Departments of ${ }^{1}$ Rehabilitation Medicine and ${ }^{2}$ Family Medicine, Kyung Hee University Medical Center, Seoul, Korea

\begin{abstract}
Objective To evaluate the association between baseline characteristics, three physical performance tests and fall history in a sample of the elderly from Korean population.

Methods A total of 307 participants (mean age, $76.70 \pm 4.85$ years) were categorized into one of two groups, i.e., fallers and non-fallers. Fifty-two participants who had reported falling unexpectedly at least once in the previous 12 months were assigned to the fallers group. Physical performance tests included Short Physical Performance Battery (SPPB), Berg Balance Scale (BBS), Timed Up and Go test. The differences between the two study groups were compared and we analyzed the correlations between fall histories and physical performance tests.

Results SPPB demonstrated a significant association with fall history. Although the BBS total scores did not show statistical significance, two dynamic balance test items of BBS (B12 and B13) showed a significant association among fallers.

Conclusion This study suggests that SPPB and two dynamic balance test items of the BBS can be used in screening for risk of falls in an ambulatory elderly population.
\end{abstract}

Keywords Elderly, Fall, Berg Balance Scale, Short Physical Performance Battery, Timed Up and Go test

\section{INTRODUCTION}

Approximately $30 \%$ of adults over 65 years old fall each year $[1,2]$. The incidence is higher for persons aged 75 years or older [3]. Physical and cognitive functions are known to declines with age [4]. This is accelerated with

Received June 21, 2016; Accepted August 24, 2016

Corresponding author: Jinmann Chon

Department of Rehabilitation Medicine, Kyung Hee University Medical Center, 23 Kyungheedae-ro, Dongdaemun-gu, Seoul 02447, Korea. Tel: +82-2958-8565, Fax: +82-2-958-8560, E-mail: pakhasu@naver.com

ORCID: Jin Chul Kim (http://orcid.org/0000-0002-4405-5463); Jinmann Chon (http://orcid.org/0000-0002-4186-6623); Hee Sang Kim (http://orcid. org/0000-0003-4985-0594); Jong Ha Lee (http://orcid.org/0000-0002-7627-6543); Seung Don Yoo (http://orcid.org/0000-0003-4513-2560); Dong Hwan Kim (http://orcid.org/0000-0002-3812-5509); Seung Ah Lee (http://orcid.org/0000-0002-3426-6259); Yoo Jin Han (http://orcid.org/0000-00033256-9931); Hyun Seok Lee (http://orcid.org/0000-0003-2994-0066); Bae Youl Lee (http://orcid.org/0000-0003-1782-5917); Yun Soo Soh (http://orcid. org/000-0001-8368-4900); Chang Won Won (http://orcid.org/0000-0002-6429-4461).

@ This is an open-access article distributed under the terms of the Creative Commons Attribution Non-Commercial License (http://creativecommons.org/ licenses/by-nc/4.0) which permits unrestricted noncommercial use, distribution, and reproduction in any medium, provided the original work is properly cited. Copyright $\odot 2017$ by Korean Academy of Rehabilitation Medicine 
other related deteriorations of various functions and prerequisites of the body to optimum physical performance among older adults, which may result in an increase in falls and related issues $[4,5]$. Falls among the elderly lead to loss of independence, hospitalization from trauma, injury-related deaths and fractures, a decrease in the quality of life, and an increase in associated health care costs $[6,7]$.

One method for the effective management of healthcare resources is preventive care that includes early detection and management of falls by the elderly. Early screening among older adults is recommended for preventive fall strategies [8]. Screening should be simple, fast, and inexpensive to perform. Previous literature has identified many factors associated with a higher risk of falls, including female sex, advancing age, gait and balance deficits, chronic disease, and medication use.

Numerous simple and composite physical performance tests have been used to screen for fall risks in older adults. Examples of simple assessment tools include the gait speed test, Timed Up and Go test (TUG), and the Five-Times-Sit-to-Stand Test. Composite tests such as Short Physical Performance Battery (SPPB) measure several physical performance tasks (e.g., sit-to-stand, standing balance, and gait speed); balance performance is assessed through functional tasks that test equilibrium, such as those used in the Berg Balance Scale (BBS).

The theoretical validity of physical performance tests has not been evaluated. Moreover, no test is designed to assess all aspects of functional mobility or fall risks. Therefore, the validity has to rely on the discriminative and predictive properties of each test. The association with fall history has been evaluated previously; some studies suggested that physical performance tests differed between people with and without a history of falls $[9,10]$. However, fall risks may be different across cultures and in different climates. Comprehensive investigations of the association between fall histories and physical performance tests in the Korean population are rare. Moreover, there is no information about the association between some of the simple and composite physical performance tests and fall risks among independent community-dwelling older adults. Therefore, it may be stated that an assessment of the association between physical performance tests and fall histories could be a prerequisite evaluation to prevent fall for the elderly. We hypothesized that age and sex, as well as three physical performance tests, would show significant differences and associations with fall history. We, therefore, evaluated associations among baseline characteristics, three physical performance tests, and histories of falls in a sample of the elderly Korean population.

\section{MATERIALS AND METHODS}

\section{Subjects}

This cross-sectional study involved 307 communitydwelling older adults (94 men and 213 women) aged 65-92 years (mean age, $76.70 \pm 4.85$ years), who were elderly people living independently in the community or in assisted and independent living institutions. Participants were recruited through advertisements placed at Dongdaemun-gu public health center in Seoul, Korea from May 2014 to April 2015. The following exclusion criteria were applied ie, inability to comprehend and follow instructions (or Mini-Mental State Examination score $<23$ ), having a known acute illnesses, current or recent fractures, ear infections (or vestibular disorders), use of drugs that could affect muscle strength and balance, inability to hold the shoulder at $90^{\circ}$ flexion, unstable chronic diseases (such as unstable diabetes mellitus and uncompensated heart failure; malignancy and musculoskeletal disorders), and neurological problems such as Parkinson disease and stroke. All participants were able to follow directions, give appropriate responses to survey questions, and participate in the interview process without assistance. Before participating in the study, all participants gave written informed consent by signing a form that summarized the purpose of the study, explained risks and adverse effects, indicated that all information gathered would remain confidential, and assured participants that they could withdraw at any time.

\section{Data collection}

Health assessments were done by using self-administered questionnaires and interviews conducted by trained staff. A standardized questionnaire covering basic demographic data, fall history, medical comorbidities, and current medication use was sent to each participant before physical examination and three physical performance tests. Physical examination included measurements of weight, height, body mass index (BMI), blood 
pressure, and the Korean version of the Mini-Mental State Examination (K-MMSE). Scores ranged from 0 to 30; higher scores suggest normality and lower scores suggest cognitive impairment.

A fall within the previous 12 months was determined by self-report. A fall was operationally defined as "a subject unintentionally coming to rest on the ground or another lower level, except those that result from a major intrinsic event (e.g., stroke or syncope) or overwhelming hazard" [2].

\section{Physical performance tests}

\section{Timed Up and Go test}

TUG test is a measure of functional mobility in older adults $[11,12]$. Participants were instructed to sit on a chair (seat height, $46 \mathrm{~cm}$; arm-rest height, $65 \mathrm{~cm}$ ) placed against the wall. Participants were instructed to stand, to walk at their normal pace on a 3-m pathway, to turn at the endpoint mark, to walk back on the determined pathway, and then to sit on a chair. Participants were not provided with any assistance and performed sessions with adequate rest between tests. The mean of three scores was taken as the TUG test score.

\section{Short Physical Performance Battery}

SPPB is a composite outcome measure of lower-limb function, including strength, endurance, gait, and balance [13]. The SPPB is composed of three tests: a hierarchical assessment of standing balance, a short walk at the usual elderly pace, and standing five times from a seated position in a chair. For balance, participants were asked to remain standing with their feet as close together as possible, then in a semi-tandem position, and finally in a tandem position. Each position had to be held for 10 seconds. The time required to travel $4 \mathrm{~m}$ at a usual pace was measured to assess gait speed. This test was repeated twice, and the analysis used the evaluation corresponding to the shortest time period. For the standing test from a chair, participants were asked to stand and sit in a chair five times as quickly as they could with arms crossed over the chest. This test was performed only after the elderly person demonstrated their ability to stand without using their arms. Previous studies have shown that the SPPB can predict disability, institutionalization, falls, and mortality among older adults [13-16]. A score ranging from 0 to 4 ( 0 , inability to complete the task; 4 , highest level of function) was given for each task in the SPPB, with the sum of these three tests (0-12) reflecting the complete measurement of physical function [13].

\section{Berg Balance Scale}

BBS has 14 items (Table 1) that assess balance during functional activities in daily life; these activities are scored from 0 to 4 , with 0 being the worst and 4 being the best performance of independent tasks. The maximum total score is 56 points. A lower score suggests impaired stability [17].

\section{Statistical analysis}

Data were analyzed using SPSS ver. 13.0 for Windows (SPSS Inc., Chicago, IL, USA). Participants' baseline characteristics were compared according to fall history, using independent t-tests for continuous variables and chi-squared tests for categorical variables. Results with p-values $<0.05$ were considered to be statistically significant.

Binary logistic regression was performed to examine independent variables (physical performance tests) that were significantly correlated with a history of falls (dependent variable). We conducted univariate analysis to identify clinical variables significantly associated with a fall history, including age, sex, blood pressure, K-MMSE, height, weight, and BMI. Next, multivariate logistic regression was performed to identify those factors that

Table 1. Berg Balance Scale and 14 items

\begin{tabular}{|cl|}
\hline Item & \multicolumn{1}{c|}{ Description } \\
\hline B1 & Sitting to standing \\
\hline B2 & Standing unsupported \\
\hline B3 & Sitting unsupported \\
\hline B4 & Standing to sitting \\
\hline B5 & Transfers \\
\hline B6 & Standing with eyes closed \\
\hline B7 & Standing with feet together \\
\hline B8 & Reaching forward with outstretched arm \\
\hline B9 & Retrieving object from floor \\
\hline B10 & Turning to look behind \\
\hline B11 & Turning 360 \\
\hline B12 & Placing alternate foot on stool \\
\hline B13 & Standing with one foot in front \\
\hline B14 & Standing on one foot \\
\hline
\end{tabular}


independently contributed to a history of falls. We also calculated adjusted odds ratios with $95 \%$ confidence intervals. A p-value of $<0.05$ was considered to be statistically significant.

\section{RESULTS}

\section{Baseline characteristics}

The characteristics of participants are shown in Table 2. Of the 307 participants, 52 (16.9\%) reported a history of falls. The study population consisted of 94 males and 213 female subjects, with a mean age of $76.70 \pm 4.85$ years. The mean K-MMSE score and BMI were $26.25 \pm 2.49$ and $28.2 \pm 4.7 \mathrm{~kg} / \mathrm{m}^{2}$, respectively.

Table 3 summarizes the baseline characteristics and results of three physical performance tests for 'fallers' and 'non-fallers'. Statistical analysis revealed no significant differences between two groups in terms of baseline characteristics, except for BMI ( $\mathrm{p}=0.009)$. The mean BMI was 24.10 and 25.33 in fallers and non-fallers, respectively, with a significantly lower BMI among fallers. In physical performance tests, SPPB scores were 6.40 and 10.07 among fallers and non-fallers, respectively, with significantly lower scores among fallers. In the sub-categories

Table 2. Baseline demographic and clinical characteristics (n=307)

\begin{tabular}{|cc}
\hline Characteristic & Value \\
\hline Age $(\mathrm{yr})$ & $76.70 \pm 4.85$ \\
\hline Sex & \\
\hline Male & $94(30.6)$ \\
\hline Female & $213(69.4)$ \\
\hline History of falls & $52(16.9)$ \\
\hline Faller & $255(83.1)$ \\
\hline Non-fallers & $133.48 \pm 8.15$ \\
\hline Systolic BP $(\mathrm{mmHg})$ & $75.06 \pm 8.26$ \\
\hline Diastolic BP $(\mathrm{mmHg})$ & $26.25 \pm 2.49$ \\
\hline K-MMSE & $153.45 \pm 13.63$ \\
\hline Height $(\mathrm{cm})$ & $59.91 \pm 8.54$ \\
\hline Weight $(\mathrm{kg})$ & $25.13 \pm 3.13$ \\
\hline BMI $\left(\mathrm{kg} / \mathrm{m}^{2}\right)$ & \\
\hline
\end{tabular}

Values are presented as mean \pm standard deviation or number (\%).

BP, blood pressure; K-MMSE, Korean version of MiniMental State Examination; BMI, body mass index. of SPPB, the balance test, gait speed test, and chair-stand test scores also showed significantly lower score among fallers than non-fallers. There was no significant difference between fallers and non-fallers (52.67 and 52.65, respectively), based on total BBS score. When 14 BBS items were analyzed separately, the scores of the fallers were significantly lower for two items-'placing an alternate foot on a stool (B12)', and 'standing with one foot in front (B13). The other 12 items on the BBS, including 'standing on one foot (B14)', showed no statistically significant difference between fallers and non-fallers. For the TUG times, statistical analysis revealed no significant differences between fallers and non-fallers.

\section{Association between physical performance tests and fall history}

Table 4 shows the correlation among three physical performance tests and fall histories in a multivariate binary logistic regression. Items in BBS, TUG, and SPPB tests that showed significant associations with falls were included in the regression model to identify the tests that were able to predict falls. SPPB showed significant correlation with fall history ( $\mathrm{p}=0.000$ for balance test, $\mathrm{p}=0.004$ for gait speed test, $\mathrm{p}=0.000$ for the chair stand test). Among the 14 items on BBS, B12 and B13 showed significant correlations with fall history ( $\mathrm{p}=0.000$ for $\mathrm{B} 12$, $\mathrm{p}=0.005$ for B13). These results persisted after adjustment for age, sex, blood pressure, K-MMSE, and BMI.

\section{DISCUSSION}

Falls have become a major public health problem in the aging population. Fall prevention is important in geriatric medicine. Evaluations of fall risks are necessary to identify a high-risk group that can serve as a control group for programs on fall prevention. Previous studies have reported many risk factors for falls, including a history of falls, lower-extremity weakness, balance and gait abnormalities, decreased muscle strength, older age, cognitive impairment, medications, orthostatic hypotension, anemia, female sex, arthritis, and psychological factors [1820].

This study explored the association among baseline characteristics, three physical performance tests, and fall history; physical performance (SPPB), dynamic and static balance (BBS), functional mobility (TUG) were evalu- 
Table 3. Demographic characteristics and physical performance tests between two groups divided by fall history $(\mathrm{n}=307)$

\begin{tabular}{|lccc}
\hline \multicolumn{1}{c}{ Variable } & Fallers $\mathbf{( n = 5 2 )}$ & Non-fallers $(\mathbf{n = 2 5 5})$ & p-value \\
\hline Age $(\mathrm{yr})$ & $76.87 \pm 4.12$ & $76.67 \pm 5.00$ & 0.788 \\
\hline Sex (male:female) & $16: 36$ & $79: 182$ & 0.943 \\
\hline Systolic BP (mmHg) & $132.38 \pm 8.41$ & $133.70 \pm 8.11$ & 0.289 \\
\hline Diastolic BP (mmHg) & $74.87 \pm 9.06$ & $75.10 \pm 8.12$ & 0.850 \\
\hline K-MMSE & $26.34 \pm 2.14$ & $26.23 \pm 2.56$ & 0.767 \\
\hline Height $(\mathrm{cm})$ & $155.07 \pm 8.10$ & $153.13 \pm 14.50$ & 0.349 \\
\hline Weight $(\mathrm{kg})$ & $58.10 \pm 8.61$ & $60.27 \pm 8.51$ & 0.940 \\
\hline BMI (kg/m $\left.{ }^{2}\right)$ & $24.10 \pm 3.22$ & $25.33 \pm 3.08$ & $0.009^{*}$ \\
\hline Physical performance tests & & & 0.968 \\
\hline BBS & $52.67 \pm 3.43$ & $52.65 \pm 3.63$ & $0.000^{*}$ \\
\hline Placing alternate foot on stool & $3.21 \pm 1.11$ & $3.89 \pm 0.33$ & $0.005^{*}$ \\
\hline Standing with one foot in front & $2.79 \pm 1.05$ & $3.25 \pm 0.87$ & 0.104 \\
\hline Standing on one foot & $2.63 \pm 1.22$ & $2.94 \pm 1.22$ & 0.382 \\
\hline TUG (s) & $11.53 \pm 3.50$ & $11.08 \pm 2.32$ & $0.000^{*}$ \\
\hline SPPB & $6.40 \pm 0.93$ & $10.07 \pm 3.04$ & $0.000^{*}$ \\
\hline Balance test & $2.04 \pm 0.34$ & $3.50 \pm 0.76$ & $0.004^{*}$ \\
\hline Gait speed test & $2.29 \pm 0.50$ & $3.32 \pm 2.57$ & $0.000^{*}$ \\
\hline Chair stand test & $2.08 \pm 0.62$ & $3.24 \pm 0.88$ & \\
\hline
\end{tabular}

Values are presented as mean \pm standard deviation.

BP, blood pressure; K-MMSE, Korean version of Mini-Mental State Examination; BMI, body mass index; BBS, Berg Balance Scale; TUG, Timed Up and Go test; SPPB, Short Physical Performance Battery.

${ }^{*} \mathrm{p}<0.05$.

Table 4. Logistic regression: association of fall history in fallers $(n=52)$

\begin{tabular}{|lccc|}
\hline \multicolumn{1}{|c}{ Variable } & OR & $\mathbf{9 5 \%}$ CI & p-value \\
\hline Age & 1.017 & $0.951-1.087$ & 0.544 \\
\hline Sex & 1.248 & $0.611-2.548$ & 0.544 \\
\hline K-MMSE & 1.022 & $0.894-1.167$ & 0.753 \\
\hline BMI & 0.874 & $0.789-0.969$ & $0.011^{*}$ \\
\hline Physical performance tests & & \\
\hline BBS & 1.023 & $0.926-1.131$ & 0.652 \\
\hline Placing alternate foot on stool (B12) & 0.168 & $0.090-0.316$ & $0.025^{*}$ \\
\hline Standing with one foot in front (B13) & 0.661 & $0.435-1.005$ & $0.045^{*}$ \\
\hline Standing on one foot (B14) & 0.881 & $0.652-1.189$ & 0.406 \\
\hline TUG & 1.069 & $0.945-1.210$ & 0.290 \\
\hline SPPB & 0.170 & $0.103-0.281$ & $0.000^{*}$ \\
\hline Balance test & 0.073 & $0.031-0.169$ & $0.000^{*}$ \\
\hline Gait speed test & 0.235 & $0.095-0.581$ & $0.002^{*}$ \\
\hline Chair stand test & 0.238 & $0.117-0.484$ & $0.000^{*}$ \\
\hline
\end{tabular}

K-MMSE, Korean version of Mini-Mental State Examination; BMI, body mass index; BBS, Berg Balance Scale; TUG, Timed Up and Go test; SPPB, Short Physical Performance Battery.

${ }^{*} \mathrm{p}<0.05$. 
ated. Fallers had significantly lower scores compared with non-fallers in the SPPB and two dynamic balance test items in the BBS (B12 and B13). The SPPB and two BBS items (B12 and B13) showed a significant association with the risk for falls among fallers. Contrary to our study hypothesis, age and sex did not show a correlation with fall history.

SPPB is a composite outcome measure of lower-limb physical performance, with three timed components to assess standing balance, gait speed, and lower-limb force (chair stand). Singh et al. [21] reported that the SPPB was significantly correlated with physiological falls. The present study also showed that the SPPB is a reliable tool for the assessment of the risk of falls in elderly individuals who were able to walk independently.

TUG is a basic test of functional mobility and reportedly has high reliability (intraclass correlation coefficient, 0.98 ) in older adults [12]. The test measures speed during several functional maneuvers, which include standing up, walking, turning and sitting down. In the present study, TUG did not show a significant difference between fallers and non-fallers, or significant association among fallers. Similar results have been reported in previous studies. Thrane et al. [22] showed that TUG cannot be used as a test for fall risks in an ambulatory elderly population. There is a statistical association between TUG times and a history of falls, but the clinical relevance of this association is limited [22]. TUG, which is one of the best-known tests for screening older adults, was not able to differentiate between fallers and non-fallers [11], in some recent studies. In the present study, TUG did not show a statistical relation. It is presumed that TUG may not be a reliable tool in the assessment of fallers and nonfallers among those who can walk independently.

BBS assesses balance performance through functional tasks that require equilibrium and is commonly used in the elderly. Previous studies have shown that BBS, as a dichotomous scale based on defined cut-off scores, is valuable for prediction of fall risks in the elderly [23]. However, in several prospective studies of fall risk for community-dweller, the use of BBS as a dichotomous scale was inadequate for the identification of the majority of people at risk of falling in the future [24]. Additionally, in a study for community-dwelling people with chronic stroke, no differences were found between subjects who fell once and subjects who did not fall or between sub- jects who fell more than once and subjects who did not fall [25]. These results demonstrate that the association of BBS scores with risks for falls in community-dwellers need further investigation. The present study showed no statistically significant difference in BBS total scores between the two groups (fallers and non-fallers) and no statistical associations among fallers. However, two of 14 BBS items (B12 and B13) showed an association with fall histories. One of the limitations in the interpretation of the BBS total score may lie in the scoring of the individual BBS items. Kornetti et al. [26] found that the score associated with success on an individual item varies among the 14 BBS items. 'Success' in this context refers to performing the defining task for a particular BBS item. To date, there has been a limited analysis of individual BBS items about fall risk in the elderly. However, Kornetti et al. [26] reported that three items-'placing an alternate foot on a stool (B12),' 'standing with one foot in front (B13)', and 'standing on one foot (B14)' - were the most difficult. As shown in the present study, a statistical association was observed for B12 and B13. Therefore, the present study is generally in agreement with Kornetti et al. [26]. Accordingly, in the case of relatively easy performance-test items, there was no difference between fallers and nonfallers among participants who were able to walk independently. In B14 (standing on one foot), however, there was no difference between the two groups, and there was no association with fall history. Both groups may have had difficulty performing B14 because balance function is diminished in the elderly. This suggests that the ability of BBS to classify individuals based on fall history is largely derived from these three items. We interpret these findings with caution, however, because study participants were high-functioning individuals and the items associated with fall histories would likely be different for lower-functioning individuals. The study results highlight the importance of matching examination tools with the functional levels study participants.

Obesity can contribute to a reduction in the ability to easily perform activities of daily living. So, it should be expected that an excessive BMI would be associated with risks for falls among older adults. However, in this study, fallers had lower BMIs. Previous prospective fall-risk cohort studies either reported that increased weight was not associated with falls in older people, or did not report associations between excessive BMIs and falls at all 
[2,28-30]. Recent studies have also reported inconsistent findings: one documented an increased prevalence of falls in middle-aged and older obese individuals (mean age younger than 60 years) [31]; one found higher risks of falls for obese individuals aged 65 years and older [32]; a third found no clear evidence of the influence of obesity on falls [33]. Therefore, large population studies may be required to uncover whether any association exists between BMI and falls.

Several previous studies have reported that age and sex were significant risk factors for falls [34]. Women, in particular, are more prone to falls and have a higher predisposition than men to fall-related injuries, namely, to osteoporotic fractures $[35,36]$. Although several authors have cited sex differences in the mechanical properties of tendons to explain the discrepancies in the risks for falling [37], the reasons for a higher incidence of falls in women are not well known. One study reported that prevalence for fallers and the annual rates of falls were higher among women than men; however when controlled for each health or physical fitness variable, the Mantel-Haenszel test revealed no differences between the percentages of the men and the women who fall [38]. The relationship of age and sex with fall risks among the elderly was inconsistent so far. In present study, age and sex were not associated with fall risks. Although several previous studies tried to find out prediction of falls, despite being considered risk factors of falls, the influence of muscle strength, flexibility, agility, body composition, and personal characteristics (such as sex) remains unclear $[39,40]$. It is presumed that a lower association between age, sex and falls is due to various other factors such as lifestyle, health status, and physical fitness. It was also found that the prevalence of falls in present study was $16.9 \%$. This result was obviously lower than the prevalence than previous study [2] in which at least $30 \%$ of people aged 65 years or older who lived in a community fell at least once a year. It may be postulated that recall bias could have affected the finding and maybe lowered the prevalence of reported falls. Because the information regarding for falls was self-reported from participants. It is presumed that the self-reporting may showed a lower prevalence rate in falls associated with age and sex relative to the other previous studies.

There are limitations in this study. First, since this was a cross-sectional survey, and the results must be inter- preted carefully. Cross-sectional studies such as this one, can detect associations among variables, but cannot demonstrate causality. A longitudinal study involving a large cohort is needed in order to be able to reach generalizable conclusions with a greater degree of confidence. Second, data on fall histories were collected retrospectively and were dependent on the participants' recollections of events 12 months prior to the onset of the study. This may have introduced recall bias. Third, the present analyses were limited by the variables available in the survey data and did not include other potential correlates or confounders. Lastly, the findings of this study may only be generalizable to a relatively healthy population of seniors living in the community and may not apply to residents of care facilities, who have different risk profiles for falls compared with the general population.

In conclusion, this cross-sectional study was performed using baseline characteristics and physical performance tests to assess associated with falls in those aged over 65 , who were followed at an outpatient public health center in Seoul, Korea.

The findings of this study suggest that SPPB and two items (B12 and B13) on the BBS are associated with a fall history. Accordingly, SPPB and those two items can be used for fall risks screening in an ambulatory elderly population. TUG and the total BBS do not show any associations with fall histories in a high-functioning elderly population. To conclude effective screening assessments in prediction of high risk group, a follow-up prospective study is needed for this cohort. Future research may explore the use of various subsets of BBS items matched to group functional levels, to more accurately identify fall risk. Additionally, more challenging, physical performance tests might reveal balance deficits that could cause falls in high- functioning individuals. The development of new tests for this population is indicated.

\section{CONFLICT OF INTEREST}

No potential conflict of interest relevant to this article was reported.

\section{REFERENCES}

1. Berg WP, Alessio HM, Mills EM, Tong C. Circumstances and consequences of falls in independent commu- 
nity-dwelling older adults. Age Ageing 1997;26:261-8.

2. Tinetti ME, Speechley M, Ginter SF. Risk factors for falls among elderly persons living in the community. N Engl J Med 1988;319:1701-7.

3. Cesari M, Landi F, Torre S, Onder G, Lattanzio F, Bernabei R. Prevalence and risk factors for falls in an older community-dwelling population. J Gerontol A Biol Sci Med Sci 2002;57:M722-6.

4. Onder G, Penninx BW, Lapuerta P, Fried LP, Ostir GV, Guralnik JM, et al. Change in physical performance over time in older women: the Women's Health and Aging Study. J Gerontol A Biol Sci Med Sci 2002;57: M289-93.

5. Lord SR, Menz HB, Tiedemann A. A physiological profile approach to falls risk assessment and prevention. Phys Ther 2003;83:237-52.

6. Kannus P. Preventing osteoporosis, falls, and fractures among elderly people: promotion of lifelong physical activity is essential. BMJ 1999;318:205-6.

7. Thiem U, Klaaben-Mielke R, Trampisch U, Moschny A, Pientka L, Hinrichs T. Falls and EQ-5D rated quality of life in community-dwelling seniors with concurrent chronic diseases: a cross-sectional study. Health Qual Life Outcomes 2014;12:2.

8. Gillespie LD, Robertson MC, Gillespie WJ, Sherrington C, Gates S, Clemson LM, et al. Interventions for preventing falls in older people living in the community. Cochrane Database Syst Rev 2012;(9):CD007146.

9. Salgado R, Lord SR, Packer J, Ehrlich F. Factors associated with falling in elderly hospital patients. Gerontology 1994;40:325-31.

10. Gunter KB, White KN, Hayes WC, Snow CM. Functional mobility discriminates nonfallers from onetime and frequent fallers. J Gerontol A Biol Sci Med Sci 2000;55:M672-6.

11. Podsiadlo D, Richardson S. The timed "Up \& Go": a test of basic functional mobility for frail elderly persons. J Am Geriatr Soc 1991;39:142-8.

12. Shumway-Cook A, Brauer S, Woollacott M. Predicting the probability for falls in community-dwelling older adults using the Timed Up \& Go Test. Phys Ther 2000;80:896-903.

13. Guralnik JM, Seeman TE, Tinetti ME, Nevitt MC, Berkman LF. Validation and use of performance measures of functioning in a non-disabled older population: MacArthur studies of successful aging. Aging (Milano)
1994;6:410-9.

14. Ostir GV, Volpato S, Fried LP, Chaves P, Guralnik JM. Reliability and sensitivity to change assessed for a summary measure of lower body function: results from the Women's Health and Aging Study. J Clin Epidemiol 2002;55:916-21.

15. Perera S, Mody SH, Woodman RC, Studenski SA. Meaningful change and responsiveness in common physical performance measures in older adults. J Am Geriatr Soc 2006;54:743-9.

16. Quadri P, Tettamanti M, Bernasconi S, Trento F, Loew F. Lower limb function as predictor of falls and loss of mobility with social repercussions one year after discharge among elderly inpatients. Aging Clin Exp Res 2005;17:82-9.

17. Bogle Thorbahn LD, Newton RA. Use of the Berg Balance Test to predict falls in elderly persons. Phys Ther 1996;76:576-85.

18. Vellas BJ, Wayne SJ, Garry PJ, Baumgartner RN. A twoyear longitudinal study of falls in 482 communitydwelling elderly adults. J Gerontol A Biol Sci Med Sci 1998;53:M264-74.

19. Kannus P, Sievanen H, Palvanen M, Jarvinen T, Parkkari J. Prevention of falls and consequent injuries in elderly people. Lancet 2005;366:1885-93.

20. Nevitt MC, Cummings SR, Kidd S, Black D. Risk factors for recurrent nonsyncopal falls: a prospective study. JAMA 1989;261:2663-8.

21. Singh DK, Pillai SG, Tan ST, Tai CC, Shahar S. Association between physiological falls risk and physical performance tests among community-dwelling older adults. Clin Interv Aging 2015;10:1319-26.

22. Thrane G, Joakimsen RM, Thornquist E. The association between timed up and go test and history of falls: the Tromso study. BMC Geriatr 2007;7:1.

23. Berg KO, Wood-Dauphinee SL, Williams JI, Maki B. Measuring balance in the elderly: validation of an instrument. Can J Public Health 1992;83 Suppl 2:S7-11.

24. Muir SW, Berg K, Chesworth B, Speechley M. Use of the Berg Balance Scale for predicting multiple falls in community-dwelling elderly people: a prospective study. Phys Ther 2008;88:449-59.

25. Harris JE, Eng JJ, Marigold DS, Tokuno CD, Louis CL. Relationship of balance and mobility to fall incidence in people with chronic stroke. Phys Ther 2005;85:150-8. 26. Kornetti DL, Fritz SL, Chiu YP, Light KE, Velozo CA. 
Rating scale analysis of the Berg Balance Scale. Arch Phys Med Rehabil 2004;85:1128-35.

27. Chiu AY, Au-Yeung SS, Lo SK. A comparison of four functional tests in discriminating fallers from nonfallers in older people. Disabil Rehabil 2003;25:45-50.

28. O'Loughlin JL, Robitaille Y, Boivin JF, Suissa S. Incidence of and risk factors for falls and injurious falls among the community-dwelling elderly. Am J Epidemiol 1993;137:342-54.

29. Campbell AJ, Borrie MJ, Spears GF. Risk factors for falls in a community-based prospective study of people 70 years and older. J Gerontol 1989;44:M112-7.

30. Lord SR, Ward JA, Williams P, Anstey KJ. Physiological factors associated with falls in older communitydwelling women. J Am Geriatr Soc 1994;42:1110-7.

31. Fjeldstad C, Fjeldstad AS, Acree LS, Nickel KJ, Gardner AW. The influence of obesity on falls and quality of life. Dyn Med 2008;7:4.

32. Himes CL, Reynolds SL. Effect of obesity on falls, injury, and disability. J Am Geriatr Soc 2012;60:124-9.

33. Rosenblatt NJ, Grabiner MD. Relationship between obesity and falls by middle-aged and older women. Arch Phys Med Rehabil 2012;93:718-22.

34. Lin CH, Liao KC, Pu SJ, Chen YC, Liu MS. Associated factors for falls among the community-dwelling older people assessed by annual geriatric health examinations. PLoS One 2011;6:e18976.

35. Swanenburg J, de Bruin ED, Uebelhart D, Mulder T. Falls prediction in elderly people: a 1-year prospective study. Gait Posture 2010;31:317-21.

36. Chu LW, Chi I, Chiu AY. Incidence and predictors of falls in the Chinese elderly. Ann Acad Med Singapore 2005;34:60-72.

37. Burgess KE, Pearson SJ, Breen L, Onambele GN. Tendon structural and mechanical properties do not differ between genders in a healthy community-dwelling elderly population. J Orthop Res 2009;27:820-5.

38. Pereira CL, Baptista F, Infante P. Men older than 50 yrs are more likely to fall than women under similar conditions of health, body composition, and balance. Am J Phys Med Rehabil 2013;92:1095-103.

39. Chodzko-Zajko WJ, Proctor DN, Fiatarone Singh MA, Minson CT, Nigg CR, Salem GJ, et al. Exercise and physical activity for older adults. Med Sci Sports Exerc 2009;41:1510-30.

40. Aoyama M, Suzuki Y, Onishi J, Kuzuya M. Physical and functional factors in activities of daily living that predict falls in community-dwelling older women. Geriatr Gerontol Int 2011;11:348-57. 